\title{
Are Single Trigger Contingent Capital Certificates an Effective Tool to Manage Risk?
}

\author{
Muhammad Ahmed Fawad * Areeba Khan ${ }^{\dagger}$
}

\begin{abstract}
The purpose of this paper is to highlight that contingent capital certificates (CC certificates) provide financial institutions with the cushion to resist financial crises, but if the structure of these CC certificates is based on singular trigger, it can cause transfer of wealth between investors i.e. existing shareholders and the CC certificate holders. Many financial institutions, till date, have issued CC certificates based on singular trigger (i.e. capital ratio/ Accounting triggers or market-based triggers) which are not as effective and reliable as multiple triggers. The paper includes a hypothetical base case to understand the triggers and case of Lehman Brothers Inc. (which filed chapter 11 bankruptcy protection on September 11th, 2008) to examine how the single trigger approach of the issuing financial institution can cause a transfer of wealth between the existing shareholders and the CC certificate holders. Book values of CC certificates are used to measure the transfer of wealth.
\end{abstract}

Keywords: Contingent capital certificates, Capital ratio/ Accounting triggers, Market based triggers, Multiple triggers, Regulatory triggers, Wealth transfer, Conversion ratio, Dilution.

\section{Introduction}

In July 2010, Frank Dodd Wall Street Reform and Consumer Protection Act was presented in response to financial crises of 2007 - 08, aimed at financial institutions to avoid economic shocks and crises. In the afore mentioned Act, the concept of contingent capital certificates (CC certificates) was presented to make financial system and financial institutions more sound and resistant to financial crises. Contingent capital certificates, also known as CoCos, $\mathrm{CC}$ certificates, Contingent capital bonds and junior debt, are type of bonds which convert to equity when the financial health of the issuer falls below a pre-specified level or when the certain trigger or triggers are met (Himmelberg \& Tsyplakov, 2012). Many financial institutions including the Lloyd's banking group, Rabobank, Credit Suisse, and Mortgage Lender Yorkshire Building Society have till date issued junior debt (Glasserman \& Nouri, 2012).

As per Corcuera et al. (2011) the aims and objectives of regulators and the financial institutions are reflected in the structure of $\mathrm{CC}$ certificates. The basic components of

\footnotetext{
* School of Business Management \& Administrative Sciences, The Islamia University of Bahawalpur, Pakistan. Email: ahmad.fawad500@live.com

${ }^{\dagger}$ Assistant Professor, School of Business Management \& Administrative Sciences, The Islamia University of Bahawalpur, Pakistan. Email: areeba.khan@iub.edu.pk
} 
the $\mathrm{CC}$ certificate structure are the trigger event, the conversion ratio (dilution), loss absorption feature and the conversion type (i.e. full vs. partial conversion). The current paper is aimed at discussing how the conversion trigger can cause transfer of wealth between existing shareholders and CC certificate holders, if the issuer is using accounting triggers or market based triggers only. The use of only one trigger can cause transfer of wealth between the two parties and can lead to unfair conversion.

Many researchers in the recent past presented the concept of multiple triggers to avoid such problems. For instance, McDonald (2013) suggested multiple triggers to convert CC certificates into equity to make the conversion manipulation free. Besides McDonald (2013); Squam Lake Working Group (2009) also suggested dual triggers to make the features of the $\mathrm{CC}$ certificates more resilient and manipulation free.

The general definition of the cushion of CC certificates is quite clear but there are many complications regarding the issuing, conversion and the identification of trigger. For instance, Rajan (2009) believes that dual triggers should be used when the bank's capital ratio falls below a certain level, when the system is in crises and the conversion is dilutive (such that when the conversion takes place it substantially dilutes the value of old equity). While on the other hand, Huertas (2009) argues that when Tier 1 capital ratio has fallen below a certain level, the conversion of the CC certificates should take place. Beside this, he also stresses on the importance of dilution. The paper presents a comprehensive review of suggestions furnished in literature to draw a clear map regarding the proposed triggers of the said security.

The aim of this study is to explain how the wealth is transferred between existing shareholder and CC certificate holders if the structure of the said security is based on single trigger (accounting or market based trigger) subject to manipulation.

\section{Literature Review}

Flannery (2009) used the term CC certificates for the first time. He argued that the number of shares to be given to the $\mathrm{CC}$ certificate holders should be determined by the contemporary market price and the terms of conversion shall make sure that they suffer no capital loss. He also believed that the conversion of CC certificates should take place a day after the trigger is reached, so that if the firms become insolvent the new shareholders may wipe out the existing shareholders. For the level of conversion, he suggested partial conversion with allocation mechanism (i.e. convert the shortest remaining maturities first). He also believed that the conversion trigger should be based on the current value of equity and scaled by the book value of assets.

The Squam Lake Working Group (2009) argues that the conversion based on the market value of the equity is subject to manipulation and suggests that instead of converting each dollar of debt into each dollar of equity, each dollar of debt should be converted to each quantity of equity to avoid market manipulation. The working group thus prefers dual trigger instead of using just market-based triggers or the capital ratio trigger. The group also suggests that conversion should take place if the two conditions are met. The first one being the declaration of a financial system crisis by the regulator and the second one 
encompassing violation by the banks of the covenants in the hybrid security. They also propose full conversion instead of partial conversion.

According to them, dependence on one of these triggers would not be effective because debt provides disciplining force to the management so it is valuable in banks capital structure. So, converting this debt to equity in a situation where a bank suffers potential losses would damage this discipline provided by the debt. If the conversion trigger based solely on the systematic crises, CC certificates are no better than debt but in extreme conditions. The regulator would also face political pressure for taking such decisions in the condition of crises, and most importantly even the financially healthy banks would be forced for conversion in crises, in which case the incentive for these banks to remain sound would evaporate.

Huertas (2009) suggests a different trigger for the conversion of CC certificates. He discusses about large, complex, cross border financial institutions, and placed these financial institutions as 'too big to fail'. To avoid failure of these institutions he suggests that the conversion of CC certificates should take place when the core Tier 1 capital of the issuer falls below a certain threshold level, the CC certificates would be converted into Tier 1 capital and upon conversion it would be fully loss absorbent. Beside this loss absorbent feature, this instrument also provides a class of investors in addition to the equity holders who will monitor the bank's financial position. He also stresses on the issue of dilution in his paper but did not specify the conversion terms.

McDonald (2013) suggests that the conversion may take place if two conditions are met; if the market value of the issuers stock falls below a pre specified level and the market index falls below a set trigger. The concept behind this dual trigger is to save the cushion of contingent capital for financial crises only. So, if during normal times a bank's performance is poor, it cannot use its cushion of CC certificates.

Allen and Tang (2016) have also proposed dual triggers and argued that the conversion of CC certificates should depend on two triggers i.e. aggregate systemic risk in the banking system and secondly the contribution of individual bank to overall systemic risk. They used the data of Lehman and Bear Stearns in their study and concluded that both the firms would have been triggered in November 2007 if these triggers were used.

Beside the suggestions of using market-based triggers and capital ratios, proposed a different trigger (D'Souza, Gravelle, Engert, Orsi, et al., 2010). In their study, they rejected market-based triggers as well as capital ratios owing to the fact that market-based triggers are too volatile while on the other hand capital ratios are too slow to reflect deterioration. They believe that SCAP (Supervisory capital assessment program) like stress test can be used to calculate a two year forward capital ratio for the firm. Researchers also believe that the issuance of CC certificates should be large enough that the firm can recapitalize even in dire circumstances. They also prefer the high level of dilution to motivate the shareholders to avoid hitting the triggers. Besides, this higher dilution terms and higher level of trigger would reduce the cost of issuing CC certificates.

Chen, Glasserman, Nouri, and Pelger (2017) argued that issuance of CC certificate is accompanied by sharp drop in equity price because of an increased level of debt. They suggested that the conversion trigger should be contractual instead of market or accounting based to avoid this hazard. This approach was significantly different than Duffie (2009), 
who proposed that the conversion should be accompanied by another sort of contingent capital to improve the cash position of the issuer. He also criticized the capital ratio trigger and preferred market-based triggers.

His argument is based on the hypothesis that if the bank uses Core Tier 1 as a trigger than there should be some concern about the failure of the accounting measures to capture the true financial position of the financial institution. For instance, Citi Bank, a SIFI (systematically important financial institution) that received significant bailout from the government in financial crises of 2008, had a Tier 1 capital ratio of $11.8 \%$ (which never fell below 7\%). When measured in December 2008 (its weakest moment) the stock market capitalization of Citi Bank fell about 1\% of its total assets or $\$ 20$ billion. Because of the limited liability treatment of equity and of significant prevailing uncertainty over the true valuation of Citibank's assets, this stock market valuation suggests that Citibank's assets probably had a market value well below its debt principal in late 2008. Nevertheless, any reasonable Tier 1 capital-based tripwire for distress-contingent convertible debt would probably not have been tripped.

Calomiris and Herring (2013) also criticize the book value trigger and believe that the book value trigger is subject to manipulation and does not reflect updated deterioration of the balance sheet. They believe that the market value of the equity or credit default swaps can be used as a trigger, and equity values can be the best trigger for the CC certificates conversion, if used properly. In their paper, they propose QSMVR (Quasi - market value of equity ratio). Under this trigger, the conversion trigger would depend on the 90 day moving average of the ratio of market value of the equity to the sum of the market value of equity and the face value of debt. The rationale behind using this moving average is to neutralize the fluctuations in the stock prices, white noise and to counter the coordinated bear run on the banks stock.

\section{Understanding Triggers}

Different market based and accounting based triggers were presented by the researchers in the past but the most frequently discussed triggers are divided into three main categories; Accounting based triggers, Market based triggers and Regulatory triggers. Beside these three main categories, multiple triggers (combination of more than one trigger) were also presented.

The trigger event is one of the most important and crucial component of the $\mathrm{CC}$ certificates structure, therefore discussed in detail. It has a direct impact on the price, risk and conversion of this junior debt.

\section{Accounting Triggers}

Accounting triggers are one of the most frequently discussed and criticized triggers of the junior debt. The trigger typically depends on the Core Equity Tier 1 ratio (CET1) of the issuer. When the CET1 ratio of the issuer falls below the specified level, the trigger is breached.

To understand triggers and their differences, let us suppose a base case of a financial 
institution. The financial institution issued (N) 10 Contingent capital certificates (F) of $\$ 100$ each with y\% return (r), 10 years to maturity (T) and the conversion would happen when the CET1 ratio of the issuer falls below $5 \%(\mathrm{r})$. The junior debt holders will receive their initial investment of $\$ 100$ if the trigger will not breach during the maturity period, and if the trigger is breached before the maturity at time $\mathrm{t}(0 \leq \mathrm{t} \leq \mathrm{T})$, then the remaining coupon payments will be cancelled and the CC certificates will be converted into equity. The graphical illustration of the trigger is shown in Figure 1.

Figure 1

Accounting trigger conversion point

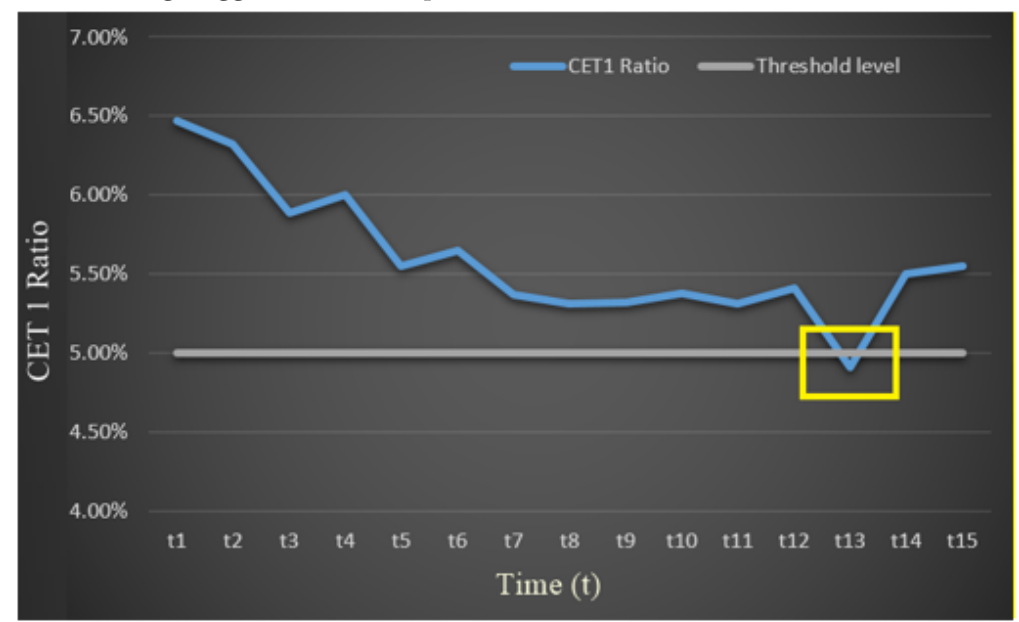

As the CET ratio of the firm falls below 5\%, the accounting trigger is breached. The junior debt is converted into the equity and the firm maintains its minimum capital requirements. The enhanced version of this accounting-based trigger also includes three months moving average of the capital ratio triggers. These triggers are up to date and reflective of the firm's current financial position.

\section{Market Based Triggers}

Dudley (2009); Pennacchi (2010) preferred market-based triggers over capital-based triggers. The rationale behind suggesting this trigger is that capital ratio triggers are less up to date with the current market conditions and market price of the issuers equity reveals the more updated financial position of the financial institution. There were many criticisms on market-based triggers, as the market prices are subject to jumps and shocks and can turn on the false alarm in some cases. To avoid this problem, moving average of market-based triggers was suggested to make the market-based triggers more stable. It also aims at elimination of the risk of false alarm due to shocks.

To understand the market-based trigger, refer to the base case discussed earlier. The firm issued $10(\mathrm{~N})$ Contingent capital certificates $(\mathrm{F})$ of $\$ 100$ each with y\% return r, 10 
years to maturity (T). The market price (S0) of firm's share is $\$ 120$ each currently, and if the market price of the firm's shares falls below the threshold level of $\$ 65 \mathrm{Cp}$ before maturity $\mathrm{T}$ at time $\mathrm{t}(0 \leq \mathrm{t} \leq \mathrm{T})$, then the $\mathrm{CC}$ certificates are converted into equity. The graphical illustration of the trigger is shown in Figure 2.

\section{Figure 2}

Market trigger conversion point

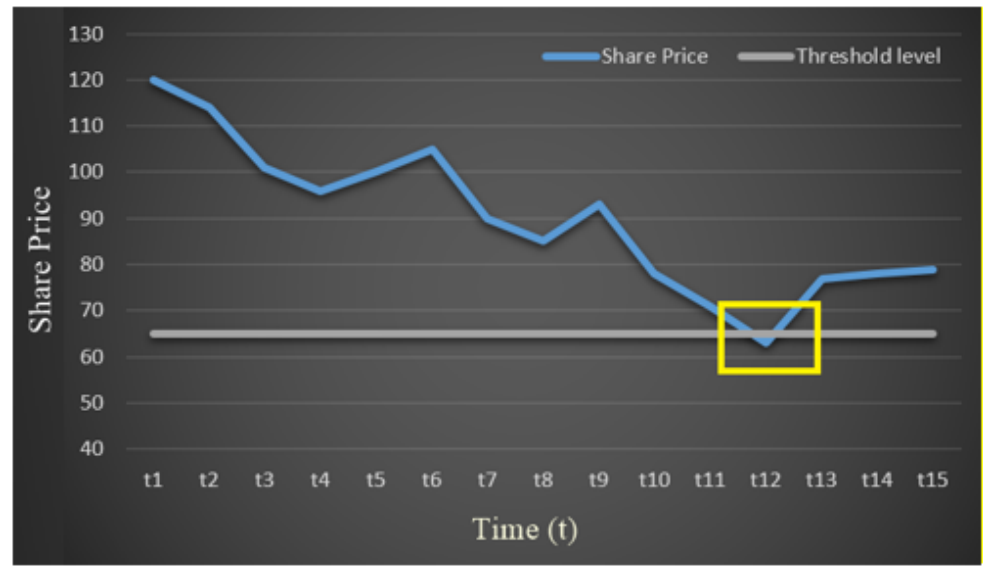

\section{Regulatory Triggers}

Contrary to the accounting and market-based triggers, under which the conversion would happen after the breach of certain limit, the regulatory trigger depends solely on the discretion of the regulator (National regulator). The aim of this trigger from regulators' point of view is to make sure that the financial institutions are holding good quality capital. Under the said trigger, the value of junior debt is eroded as there is no specific point declared to the owner of the junior debt below which his contingent capital certificates would convert into equity.

\section{Multiple Triggers}

To make this trigger system more sound, multiple triggers were suggested by Flannery (2009) and by the Squam Lake Working Group (2009) on Financial Regulation (2009). Multiple trigger system suggests two or more triggers to breach simultaneously to make the conversion happen. McDonald (2013) also suggests dual triggers for CC certificates and believes that $\mathrm{CC}$ certificates should convert into equity when the stock price of the issuing financial institution falls below a threshold level along with market index. The dual trigger concept depends on the overall financial condition of the market as well as the financial position of the issuer.

The two main advantages of this multiple trigger are (1) manipulation free conversion (as the accounting triggers and market-based triggers may be subject to manipulation) (2) the contingent capital instruments can only be used in the event of financial crisis, 
not to improve the financial performance of the firm during normal times. But there are also some drawbacks of this trigger, for instance, SIFIs (systematically important financial institutions) could not convert their CC certificates into equity if they are in financial distress and the market is performing normal, which may lead to government bailouts or financial crises.

Refer to the base case where the firm issued a CC certificate $(\mathrm{F})$ of $\$ 100$ each with y\% return (r), 10 years to maturity (T). The market price (S0) of firm's share is $\$ 120$ each currently, and if the market price of the firm's shares falls below the threshold level of $\$ 65$ Cp before maturity $(\mathrm{T})$ at time $\mathrm{t}$ and the market index falls below 90 than the CC bonds are converted into equity. The graphical illustrations are shown in Figure 3 and 4.

\section{Figure 3}

Multiple trigger conversion point

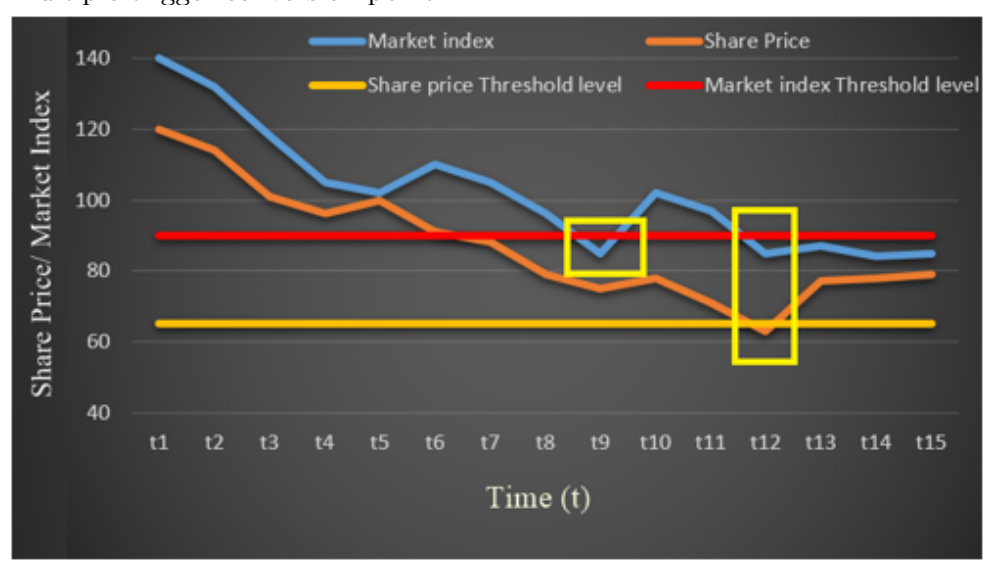

\section{Figure 4}

Multiple trigger conversion point

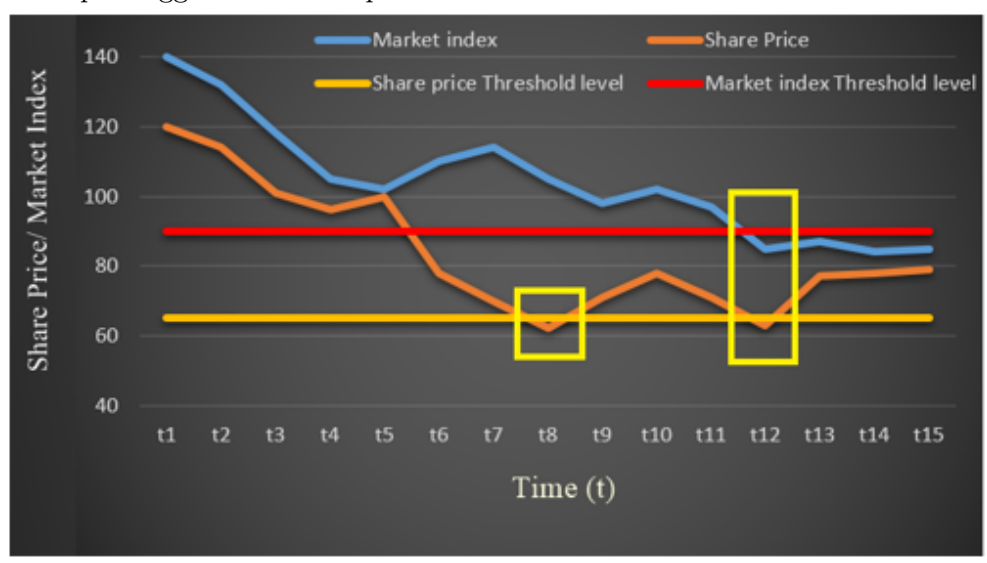

With reference to the base case, in Figure 3 there are two important points when the 
market index falls below threshold level, but the trigger was breached when the index trigger breached along with the market price trigger. The first point when the index trigger was breached indicates the situation where the market is facing financial crises but the financial institution was healthy enough to withstand the crises. In the second point, the market index trigger was breached along with the market price trigger which shows that the financial institution is also in financial crises along with the market.

The case shown in Figure 4 also has two points when the share price of the issuer falls below the pre-specified level. The first point shows the fall of market price of the issuer below the threshold level, which might be subjected to manipulation so the trigger was not breached. In second point, when the same trigger is breached along with the market index the $\mathrm{CC}$ certificates are converted into equity. The multiple trigger is effective in both cases, as in first case, if the financial institution is healthy enough to withstand the crises without the mandatory conversion, the multiple trigger will not be breached. While in the second case, if the market price of the equity is subject to manipulation the trigger will not breach either to avoid any false alarm.

\section{The Conversion Ratio (Dilution)}

The next important component of CC certificates structure is the conversion ratio. From the existing shareholder's point of view, it is the most important component because its terms and conditions can be highly dilutive for them after the conversion of the junior debt into equity. The conversion ratio defines how much share the CC certificate holders will get if the trigger is breached.

The possible conversion levels according to Corcuera et al. (2011) for conversion price $(\mathrm{Cp})$ are floating, fixed and floored.

$$
- \text { Floating } C p=M p
$$

Let $M p$ be the market price of share at time $t$. So, if $C p=M \mathrm{p}$ then such terms are very dilutive for the existing shareholders, keeping in mind the financial position of the issuing financial institution which is converting its $\mathrm{CC}$ certificates into equity due to financial distress.

$$
\text { -Fixed } C p=S 0
$$

$\mathrm{S} 0$ is the share price of the issuer at the time of issuance of $\mathrm{CC}$ certificates. This conversion condition is much less dilutive as compared to the floating conversion to the existing shareholders.

$$
\text { -Floored } C p=\max (M p ; S f)
$$

Under floored conversion, a floored price $(S f)$ is set to avoid the huge price drops thus, limiting the transfer of wealth. In case the price drops are huge, then the $S f$ is used as $C p$, and if the price drop is above the floored level, then $M p$ at time $t$ is used as $C p$.

The conversion ratio can also affect the trigger of the $\mathrm{CC}$ certificates. For instance, if the conversion terms of the $\mathrm{CC}$ certificates are more dilutive to existing shareholders, than $\mathrm{CC}$ certificate holder might try trigger manipulation (market price or accounting triggers 
only) to make the conversion happen, which in return transfer the wealth from existing shareholders to the newly converted CC certificate holders. The existing shareholders prefers the conversion to higher price level or set floored conversion price to limit the dilution to its minimum, while the $\mathrm{CC}$ holders would like to have a low conversion price to force the maximum dilution. In either case, wealth will be transferred from one party to the other which also makes CC certificate triggers (market and accounting triggers) subject to manipulation. The above discussion suggests that the conversion amount $\mathrm{Ca}$ is the number of shares the CC certificate holder would receive on conversion at time $t$ where $T$ is maturity of $\mathrm{CC}$ certificates and $t$ is the trigger event $(0 \leq \mathrm{t} \leq \mathrm{T})$. If $C p$ is the conversion price and $F$ is the face value of the $\mathrm{CC}$ certificate. So, the conversion amount would be:

$$
C a=F / C p
$$

Now, to understand the dilution perspective using equation 1, let us refer to our base case with market-based trigger illustration. Using the conversion price, $C p, \$ 65$ and the Face value, $F$ of $\$ 100$, upon the conversion the CC certificate holder would get $C a$ number of shares:

$$
\begin{gathered}
C a=100 / 65 \\
C a=1.54 \text { shares per CC Certificate }
\end{gathered}
$$
$(C a)$ :

If we just increase the conversion price to $\$ 70$, we get the following conversion amount

$$
C a=100 / 70
$$

\section{$C a=1.43$ shares per $C C$ Certificate}

Figure 5

Relationship between $C a$ and $C p$

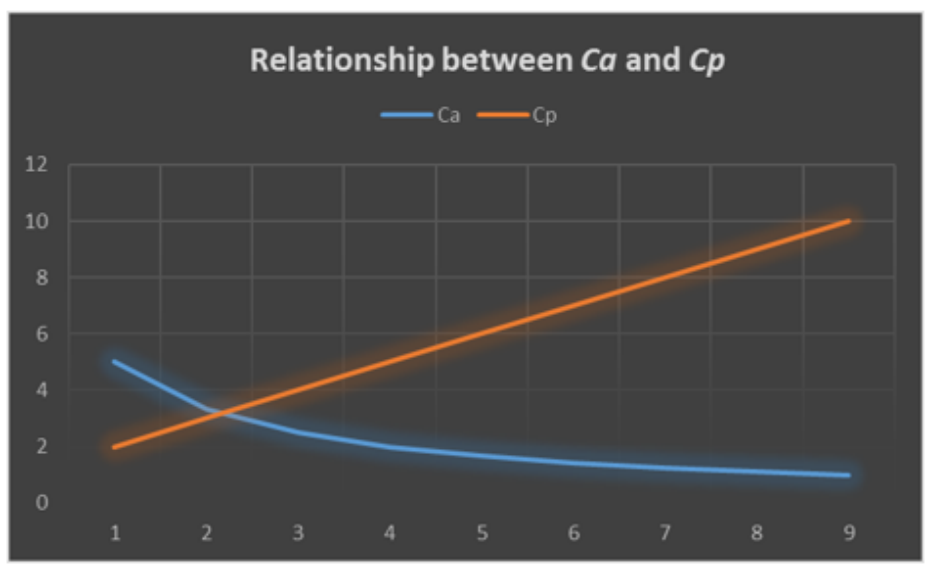


As we increased the value of $C p$ from $\$ 65$ to $\$ 70$, the value of $C a$ dropped, which results in less shares per $\mathrm{CC}$ certificate and less dilution. The relationship between $\mathrm{Ca}$ and $\mathrm{Cp}$ is also shown in Figure 5.

Talking about dilution, researchers have contradictory point of views. Some prefer maximum dilution, while others suggest minimum dilution. To understand how this phenomenon works and transfers wealth from one party to the other the current study takes into account case of Lehman Brothers Holdings Inc. which filed chapter 11 bankruptcy protection on September 11th, 2008.

\section{Research Methodology}

To understand how wealth is transferred if the structure of CC certificate is based on single trigger the base case of Lehman Brothers Holdings Inc. is used. Data sources are secondary and are collected from the financial statements of the firm for year 2008. The share prices are retrieved from yahoo finance. However, in the hypothetical scenario it is assumed that the company has issued $\mathrm{CC}$ certificates of worth $\$ 1$ million, 16 months before filing bankruptcy. The calculations are divided into three cases of wealth transfer and comparisons are made at the end of calculations.

\section{Primary Testing}

On May 31st 2007, the market price of Lehman Brothers common share was $\$ 61.92$ each. Total outstanding common shares $(I)$ were 531 million. To perform our calculations, we assume that on May 31st, 2007 the bank issued 1,00,000 $(N)$ Contingent capital certificates $(F)$ of $\$ 100$ each, worth $\$ 10 \mathrm{~m}(J)$ with y\% return $(r), 10$ years to maturity $(T)$. If the market price of the Lehman Brothers Inc. falls below the threshold level of $\$ 27$ before maturity $(T)$ at time $t(0 \leq \mathrm{t} \leq \mathrm{T})$, then the $\mathrm{CC}$ certificates are converted into equity. The case is summarized is table 1 .

\begin{tabular}{|c|c|c|c|c|c|c|}
\hline I & $*$ SO & $\mathbf{E}=\mathbf{I} * \mathbf{S 0}$ & Senior Debt & $\mathbf{N}$ & $\mathbf{F}$ & $\mathbf{J}=\mathbf{N}^{*} \mathbf{F}$ \\
\hline $531 \mathrm{~m}$ & $\$ 27.27$ & $\$ 14.5 \mathrm{bn}$ & $\$ 668.5 \mathrm{~m}$ & $1,00,000$ & $\$ 100$ & $10 \mathrm{~m}$ \\
\hline
\end{tabular}

Using these data, we analyze the dilution effect in three conversion price $(C p)$ situations, under all three scenarios market price of the issuer falls below $\$ 27$. The case \# 01 shows how manipulation of trigger transfers wealth from existing shareholders to CC certificate holders or new shareholders.

The case \# 02 explains the transfer of wealth from CC certificate holders to existing shareholders in case of floored Cp i.e. $\max M p ; S f$ where $S f>M p$ at the time of conversion. In last case, the market price of equity falls below a threshold level without any manipulation and fair conversion happens without any transfer of wealth. In all three cases the interest rates and the impact of trigger on the value of $\mathrm{CC}$ certificates is kept constant and the face value of $\mathrm{CC}$ certificates is used to find the transfer of wealth. 
Under case \# 1 the fair market value of the stock is manipulated by the bond holders to make the conversion happen, which in turn results the wealth transfer from shareholders to $\mathrm{CC}$ certificate holders. Consequently, the market price of the issuer falls below $\$ 27$ per share which breached the trigger and forced mandatory conversion.

On June 10th, 2008, the market price of Lehman Brothers Inc. share was at $\$ 27.27$, which dropped by more than $13 \%$ the very next day and closed at $\$ 23.55$ on June 11 th, 2008. We assume that this price drop was because of the manipulation by the CC certificate holders to force mandatory conversion.

In case \# 02, we assume that as a result of the financial crisis, the market price of the Lehman Brothers Inc. share declined to $\$ 23.55$ on June 11th, 2008 and $C p$ was floored at $\$ 27$ (which is the threshold level).

In case \# 03 we assume $C p=M p$, where the market price of the Lehman Brothers Inc. dropped below $\$ 27$ per share due to poor performance of the bank or financial crises.

\section{Case \# 01: Transfer of Wealth from Existing Shareholders to CC Certificate Holders}

To find out the dilution effect, first we need to find the number of shares $(\mathrm{Ca}) \mathrm{CC}$ certificate holders would get after conversion using equation 1 with $\mathrm{Cp}=23.55$ :

$$
C a=100 / \$ 23.55=4.24
$$

On June 11th, 2008 after conversion CC certificate holders would have received 4.24 shares against each CC certificate, so the total number of shares after conversion $(I c)$ would be:

$$
\begin{gathered}
\text { Number of shares after conversion }(I c)=C a * N+I \\
I c=4.24 * 1,00,000+5,31,887,439 \\
I c=532.30 m \text { shares }
\end{gathered}
$$

After getting the new number of shares after conversion, we can find the diluted value of shares $(S d)$ after conversion by using the manipulated value of equity $(E d)$ after conversion and the value of $(I c)$.

$$
\begin{gathered}
\text { Diluted value of shares }(S d)=E d / I c \\
S d=12,537,385,285 / 532,312,018.80 \\
S d=\$ 23.55
\end{gathered}
$$

The price of $\$ 23.55$ per share is the diluted price per share due to the manipulation of share price by CC certificate holders to force mandatory conversion. To find the transfer of wealth from shareholders to $\mathrm{CC}$ certificate holders first we need to find the real value of equity $(\mathrm{Er})$ and the real value of shares $(S r)$. To find this, the share price of Lehman Brothers Inc. on July 10th, 2008 will be used. 
The real value of shares can be calculated by using:

$$
\begin{gathered}
\text { Real value of equity }(E r)=E+J \\
E r=14,505,368,293+10,000,000 \\
E r=\$ 14.51 b n
\end{gathered}
$$

Using Er we can find the value of Sr:

$$
\begin{gathered}
S r=E r / I c \\
S r=\$ 14,505,368,293 / 532,312,018.80 \\
S r=\$ 27.24 \text { per share }
\end{gathered}
$$

The real value of shares is $\$ 27.24$, because the conversion was forced due to manipulation and now we have new shares $(I c)$ with total real value of equity $(E r)$. To find the transfer of wealth from existing shareholders to new shareholders (CC certificate holders), we can use:

$$
\begin{gathered}
\text { Wealth transfer to CoCo holders }(W c)=(S r-S d) * C a * N \\
\qquad \begin{array}{c}
W c=(\$ 27.24-\$ 23.55) * 4.24 * 1,00,000 \\
W c=3.70 * 4.24 * 1,00,000 \\
W c=\$ 1.57 m
\end{array}
\end{gathered}
$$

So, the total transfer of wealth from existing shareholders to new shareholders (CC certificate) is $\$ 1.57$ million. This manipulation of market price of the equity caused severe dilution and transfer of wealth. To avoid this manipulation effect Multiple triggers were suggested by many researchers. The trigger used in this case was market-based trigger; accounting based triggers are also subject to manipulation and can result in unjustified dilution and transfer of wealth.

\section{Case \# 02: Transfer of Wealth from CC Certificate Holders to Existing Share- holders}

To measure the new share price after conversion, first we need to find Ca with the conversion condition $\mathrm{Cp}=\max M p ; S f$, where $S f>M p$. Using equation 1 we get:

$$
\begin{gathered}
C a=F / C p \\
C a=100 / 27 \\
C a=3.70 \text { shares per } C C \text { certificate }
\end{gathered}
$$

After conversion on June 11th, 2008 each CC certificate holder of Lehman Brothers Inc. would have received 3.70 number of shares against each $\mathrm{CC}$ certificate. Using $\mathrm{Ca}$, we can find the total number of shares after conversion using equation 2 :

$$
\text { Number of shares after conversion }(I c)=C a * N+I
$$




$$
\begin{gathered}
I c=3.70 * 1,00,000+531,887,439 \\
I c=532.25 m
\end{gathered}
$$

Total number of shares after conversion is $532.25 \mathrm{~m}$, including $531,887,439$ existing shares and 370,370 new shares. Now, we will find the real value of equity using equation 4 :

$$
\begin{gathered}
\text { Real value of equity }(E r)=E+J \\
E r=(23.55 * 531,887,439)+10,000,000 \\
E r=\$ 12.53 b n
\end{gathered}
$$

The total value of equity after conversion is $\$ 12.53 \mathrm{bn}$. Because price was floored at $\$ 27$, while the market price of the equity was $\$ 23.55$ at the time of conversion, there is some wealth transfer between existing and new shareholders. To find the transfer of wealth from CC certificate holders to existing shareholders we can use:

$$
\begin{gathered}
\text { Wealth transfer to existing shareholders }(W s)=E r-(M p * I c) \\
\qquad \begin{array}{c}
W s=12,537,385,285-(23.55 * 532,257,809.40) \\
W s=12,537,385,285-12,536,108,507 \\
W s=\$ 1.27 m
\end{array}
\end{gathered}
$$

The total transfer of wealth from CC certificate holders to existing shareholders is $\$ 1.27 \mathrm{~m}$ because the $S f>M p$ in floored conversion. The transfer of wealth would be greater if the distance between $S f$ and $M p$ is increased. The bond holders lose the total value of $\$ 1.27 \mathrm{~m}$ from their original investment. The loss to bondholders can also be calculated by using equation 8 :

$$
\begin{gathered}
\text { Loss to } C C \text { holders } L c=J-(((F / C p) * N) * M p) \\
L c=10,000,000-(((100 / 27) * 100,000) * 23.55) \\
L c=10,000,000-(((3.70) * 100,000) * 23.55) \\
L c=10,000,000-((3,70,370.37) * 23.55) \\
L c=10,000,000-(87,23,222.22) \\
L c=\$ 1.27 m
\end{gathered}
$$




\section{Case \# 03: Fair conversion with no transfer of wealth}

Assuming $C p=M p$, and the share price of the financial institution falls to $\$ 23.55$ due to poor performance or financial crises. Using equation 1 we can find the new number of shares after conversion:

$$
\begin{gathered}
\text { Numberof sharesafterconversion }(I c)=C a * N+I \\
I c=4.24 * 100,000+531,887,439 \\
I c=532.31 \text { mshares }
\end{gathered}
$$

After conversion the total number of shares is $532.31 \mathrm{~m}$, now we will find the total value of equity after conversion using equation 4 :

$$
\begin{gathered}
\text { Realvalueofequity }(E r)=E+J \\
E r=(23.55 * 531,887,439)+10,000,000 \\
E r=12,527,385,285+10,000,000 \\
E r=\$ 12.53 b n
\end{gathered}
$$

The new value of equity after conversion is $\$ 12.53 \mathrm{bn}$ including the $\$ 10,000,000$ from the newly converted shareholders, and $\$ 12,527,385,285$ from the existing shareholders. Using new value of equity and the new number of shareholders, we can find the transfer of wealth between $\mathrm{CC}$ certificate holders and the existing shareholders. To find the transfer of wealth form CC certificate holders to existing holders using equation 7 :

$$
\begin{gathered}
\text { Wealth transfer to existing shareholders }(W s)=E r-(M p * I c) \\
\qquad \begin{array}{c}
W s=12,537,385,285-(23.55 * 532,312,018.80) \\
W s=12,537,385,285-12,537,385,285 \\
W s=\$ 0
\end{array}
\end{gathered}
$$

So, using the market price for conversion without any manipulation and using $M p=$ $C p$ there is no transfer of wealth form $\mathrm{CC}$ certificate holders to existing shareholders. Using equation 6 we can also find the transfer of wealth from existing shareholders to CC certificate holders:

$$
\begin{gathered}
\text { WealthtransfertoCCcertificateholders }(W c)=(S r-S d) * C a * N \\
\qquad c=(23.55-23.55) * 4.24 * 100,000 \\
W c=0 * 424,579.80 \\
W c=\$ 0
\end{gathered}
$$

So, in third case there is no transfer of wealth between existing shareholders and new shareholders and fair conversion happened. If Lehman Brothers Inc. issued CC certificates of $\$ 10 \mathrm{~m}$ before crises, it would have provided the bank a cushion of $\$ 10 \mathrm{~m}$ to resist the crises and might have helped the bank to fight crises a little longer. 


\section{Conclusion}

CC certificates can provide banks with the cushion they need in the event of crises. It can cause transfer of wealth between existing shareholders and the CC certificate holders if the triggers are subject to manipulation. The chances of transfer of wealth from existing shareholders to CC certificate holders are high as the market prices of shares are not only subject to manipulation but also price jumps and shocks which can turn on false alarm and as a result cause unnecessary conversion, dilution, and transfer of wealth. Flannery (2009); Squam Lake Working Group (2009) on Financial Regulation (2009) also suggested multiple triggers in their studies, the results of the study are consistent with them.

Moreover, in all three cases the face value is used instead of the market price of the $\mathrm{CC}$ certificates; the results would have been a little different otherwise. For instance, if the $\mathrm{CC}$ certificates are frontline or high trigger $\mathrm{CC}$ certificates and there is an increase in the market interest rates, the market price of $\mathrm{CC}$ certificates would reduce the transfer of wealth in second case, as the market price of $\mathrm{CC}$ certificates would not be equal to the face value. The market interest rates and the probability of conversion can magnify or reduce the transfer of wealth. In first case, where Mp is manipulated by $\mathrm{CC}$ certificate holders, if the market price of $\mathrm{CC}$ certificate is considered below its face value then the transfer of wealth would be increased and in second case where the wealth is transferred from CC certificate holders to existing shareholders the transfer of wealth would be reduced. In case of decline in market interest rates, we can expect the opposite results. Table 2 summarizes the comparison between all three cases of wealth transfer.

\begin{tabular}{lcccc} 
Table 2 & \multicolumn{1}{l}{ Ic } & Ws & Wc & Er \\
\hline Conversion Price & $532.31 \mathrm{~m}$ shares & $\$ 0.00$ & $\$ 1.57 \mathrm{~m}$ & $\$ 14.51 \mathrm{bn}$ \\
\hline $\mathrm{Cp}=\mathrm{Mp}($ manipulated $)$ & $532.25 \mathrm{~m}$ shares & $\$ 1.27 \mathrm{~m}$ & $\$ 0.00$ & $\$ 12.53 \mathrm{bn}$ \\
$\mathrm{Cp}=\max \{\mathrm{Mp} ; \mathrm{Sf}\}$, & $532.31 \mathrm{~m}$ shares & $\$ 0.00$ & $\$ 0.00$ & $\$ 12.53 \mathrm{bn}$ \\
where $\mathrm{Sf}>\mathrm{Mp}$ & & & & \\
$\mathrm{Cp}=\mathrm{Mp}$ &
\end{tabular}

The conversion terms alongside the trigger can also drive the return on the CC certificates. CC certificates with higher conversion price may demand a high premium for losing additional wealth alongside coupons if the trigger is breached; although it is not the only component of $\mathrm{CC}$ certificates structure that defines the premium of CC certificates, CC certificates with high triggers are also supposed to have high premium because they are the ones to absorb the first shock if the performance of the firm declines.

The structure of the CC certificates issued till date by some financial institutions is based on singular triggers only (accounting triggers or market-based triggers) which can cause transfer of wealth between existing shareholders and the contingent capital holders at the time of conversion. The aim of this paper is to illustrate that $\mathrm{CC}$ certificates provide cushion to resist the crises but if the structure of these certificates is based on singular trigger i.e. market based or accounting trigger, which can be manipulated and can cause transfer of wealth between the shareholders and the bondholders. Researchers and financial institutions should work on the conversion of the CC certificates to make these triggers more effective and reliable, to help make the security more useful and the financial system more sound and resilient. 


\section{References}

Allen, L., \& Tang, Y. (2016). What's the contingency? A proposal for bank contingent capital triggered by systemic risk. Journal of Financial Stability, 26, 1-14.

Calomiris, C. W., \& Herring, R. J. (2013). How to design a contingent convertible debt requirement that helps solve our too-big-to-fail problem. Journal of Applied Corporate Finance, 25(2), 39-62.

Chen, N., Glasserman, P., Nouri, B., \& Pelger, M. (2017). Contingent capital, tail risk, and debt-induced collapse. The Review of Financial Studies, 30(11), 3921-3969.

Corcuera, J. M., De Spiegeleer, J., Ferreiro-Castilla, A., Kyprianou, A. E., Madan, D. B., \& Schoutens, W. (2011). Efficient pricing of contingent convertibles under smile conform models. Available at SSRN 1954671.

D'Souza, C., Gravelle, T., Engert, W., Orsi, L., et al. (2010). Contingent capital and bail-in debt: Tools for bank resolution. Financial System Review, 12 .

Dudley, W. (2009). Financial market turmoil: the federal reserve and the challenges ahead (Tech. Rep.). Federal Reserve Bank of New York.

Duffie, D. (2009). Contractual methods for out-of-court restructuring of systemically important financial institutions. Submission Requested by the US Treasury Working Group on Bank Capital, draft of November, 9 .

Flannery, M. J. (2009). Market-valued triggers will work for contingent capital instruments. Solicited Submission to US treasury working group on bank capital.

Glasserman, P., \& Nouri, B. (2012). Contingent capital with a capital-ratio trigger. Management Science, 58(10), 1816-1833.

Himmelberg, C. P., \& Tsyplakov, S. (2012). Pricing contingent capital bonds: Incentives matter. In European financial management association conference barcelona (Vol. 2012, pp. 1-62).

Huertas, T. F. (2009). Too big to fail, too complex to contemplate: What to do about systemically important firms. Financial Markets Group, London School of Economics, September, 15.

McDonald, R. L. (2013). Contingent capital with a dual price trigger. Journal of Financial Stability, 9(2), 230-241.

Pennacchi, G. (2010). A structural model of contingent bank capital. FRB of Cleveland Working Paper No. 10-04.

Squam Lake Working Group. (2009). An expedited resolution mechanism for distressed financial firms: Regulatory hybrid securities. Council on Foreign Relations, 10. 